\title{
Microsecond precision of interaural time differences processing in the medial superior olive studied by a computational model
}

\author{
Petr Marsalek ${ }^{1,2^{*}}$, Zbynek Bures $^{3}$ \\ From Twenty Second Annual Computational Neuroscience Meeting: CNS*2013 \\ Paris, France. 13-18 July 2013
}

The medial superior olive (MSO) neural circuit in auditory brainstem computes sound azimuth from the interaural time difference (ITD) [1]. High spike timing precision in the order of tens of microseconds is necessary for this neural computation. This makes the MSO an ideal object to study spike time codes, as the relevant information is encoded by the spike timing relative to sound phase.

In the MSO, spike timing precision deteriorates towards higher sound frequencies. Experimental recordings of Joris [4] demonstrate this by the vector strength (VS) function (see Figure 1A). To explore the effects of the spike timing jitter on the MSO performance, we have introduced a model of the MSO circuit [2,3]. In our previous work, the model was explored using simulations, giving the value ranges of MSO circuit parameters which are necessary for proper functioning of the MSO in mammals [1]. In the present work we complement the simulations with several fits of smooth functions to the data and with analytical calculations. Figure. 1A shows the shortest ITD detected by the model circuit, with its minimal value at sound frequency $1 \mathrm{kHz}$. Figure. 1B shows the MSO circuit precision in dependence on the spike timing jitter, which is defined
A

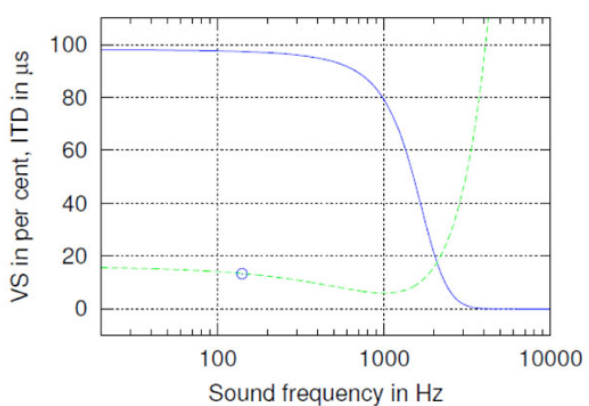

B

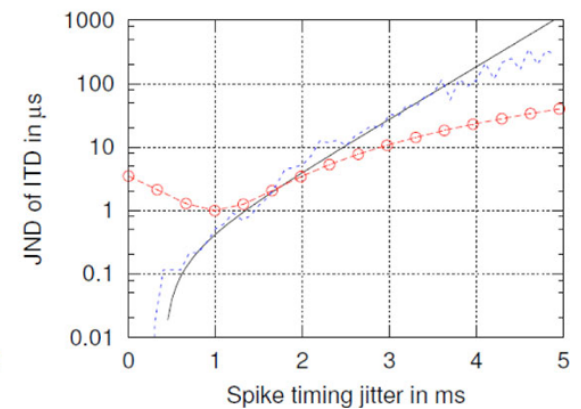

Figure 1 MSO precision in dependence on sound frequency and spike timing jitter. (A) Vector strength (VS), in units per cent shown together with the smallest detectable ITD in $\mu$ s in dependence on sound frequency. Sound frequency $140 \mathrm{~Hz}$ used in [2] is shown by circle. (B) Just noticeable difference of interaural time difference depending on variation of the spike timing jitter. Jagged line: simulated data from [3], solid line: an exponential fit to the simulations under the assumption of arbitrary time precision in the model circuit, line with circles: a quadratic function estimate of spike timing precision in a system with realistic noise.

\footnotetext{
* Correspondence: Petr.Marsalek@LF1.CUNI.CZ

${ }^{1}$ Institute of Pathological Physiology, First Medical Faculty, Charles University

in Prague, U Nemocnice 5, 128 53, Praha 2, Czech Republic

Full list of author information is available at the end of the article
} 
as standard deviation of individual spike times relative to the sound phase. Figure 1B compares the simulated system, jagged line, and exponential curve fitted to the simulation with the analytical estimates of the just noticeable difference (JND) of ITD, line with circles.

\section{Acknowledgements}

Supported by MPO FR-TI3/869 by the Ministry of Industry and Trade of the Czech Republic to P. M. and by the project M00176 "Elektronicko-

biomedicinska kooperace" at the College of Polytechnics Jihlava to Z. B.

\section{Author details}

'Institute of Pathological Physiology, First Medical Faculty, Charles University in Prague, U Nemocnice 5, 128 53, Praha 2, Czech Republic. ${ }^{2}$ Faculty of Biomedical Engineering, Czech Technical University in Prague, Nam. Sitna 3105, 272 01, Kladno, Czech Republic. ${ }^{3}$ College of Polytechnics, Tolsteho 16, 586 01, Jihlava, Czech Republic.

Published: 8 July 2013

\section{References}

1. Grothe B, Pecka M, McAlpine D: Mechanisms of sound localization in mammals. Physiol Rev 2010, 90:983-1012.

2. Sanda P, Marsalek P: Stochastic interpolation model of the medial superior olive neural circuit. Brain Res 2012, 1434:257-265.

3. Sanda P: Jitter effect on the performance of the sound localization model of medial superior olive neural circuit. Eur J Biomed Informatics 2011, 7:51-54.

4. Joris PX: Envelope coding in the lateral superior olive. II. Characteristic delays and comparison with the responses in the medial superior olive. J Neurophysiol 1996, 76:2137-2156.

doi:10.1186/1471-2202-14-S1-P46

Cite this article as: Marsalek and Bures: Microsecond precision of interaural time differences processing in the medial superior olive studied by a computational model. BMC Neuroscience 2013 14(Suppl 1): P46.

\section{Submit your next manuscript to BioMed Central and take full advantage of:}

- Convenient online submission

- Thorough peer review

- No space constraints or color figure charges

- Immediate publication on acceptance

- Inclusion in PubMed, CAS, Scopus and Google Scholar

- Research which is freely available for redistribution

Submit your manuscript at www.biomedcentral.com/submit
C Biomed Central 